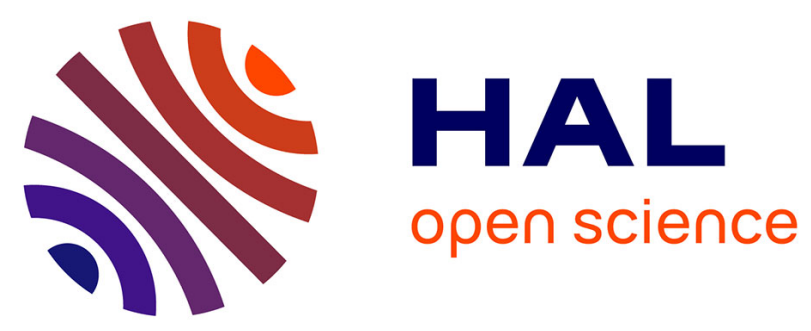

\title{
Estimation of 100-year-return-period temperatures in France in a non-stationary climate: results from observations and IPCC scenarios
}

\author{
Carine Laurent, Sylvie Parey
}

\section{- To cite this version:}

Carine Laurent, Sylvie Parey. Estimation of 100-year-return-period temperatures in France in a nonstationary climate: results from observations and IPCC scenarios. Global and Planetary Change, 2007, 57, pp.177-188. 10.1016/j.gloplacha.2006.11.008 . hal-01568964

\author{
HAL Id: hal-01568964 \\ https://hal.science/hal-01568964
}

Submitted on 26 Jul 2017

HAL is a multi-disciplinary open access archive for the deposit and dissemination of scientific research documents, whether they are published or not. The documents may come from teaching and research institutions in France or abroad, or from public or private research centers.
L'archive ouverte pluridisciplinaire HAL, est destinée au dépôt et à la diffusion de documents scientifiques de niveau recherche, publiés ou non, émanant des établissements d'enseignement et de recherche français ou étrangers, des laboratoires publics ou privés. 


\title{
Estimation of 100-year-return-period temperatures in France in a non- stationary climate : results from observations and IPCC scenarios.
}

\author{
C. Laurent and S. Parey* \\ Electricité de France, Research \& Development \\ * Corresponding author \\ E-mail addresses: sylvie.parey@edf.fr (S.Parey), carine.laurent@edf.fr (C.Laurent) \\ Phone: +3313087 76 14/ Fax: +33130877108
}

\begin{abstract}
Reference daily series of maximum temperature observed by Météo-France are used to extract the extreme values (maximum per block of time, or values above a threshold) and test the significance of a temporal polynomial trend. When the trend is statistically significant, the Peak Over Threshold method, used for very large or extreme values of stationary stochastic processes, is extended to the non-stationary case to define a new return-level. Extrapolated observed temperatures in a non-stationary climate are then compared with temperatures simulated in A2 and B2 IPCC scenarios, with Météo-France and IPSL atmospheric models in the framework of a French project called IMFREX (from April 2003 to April 2005) coordinated by Météo-France. Most of the 55 reference daily series studied indicate a quadratic evolution of the Poisson process intensity and a stationary Pareto scale parameter from the 1960s or 1970s to 2002, indicating more frequent exceedances at the end of the $20^{\text {th }}$ century. Extrapolation of the significant observed trends allow to reach the low level of centennial temperatures simulated by the atmospheric models for the end of the $21^{\text {st }}$ century.
\end{abstract}

Keywords : extreme temperatures, trend, non-stationary, climate change, return-level, POT. 


\section{Introduction}

A trend during the $20^{\text {th }}$ century in mean surface air temperature is now admitted. In a climate change context, and after the recent occurrence of extreme meteorological events in France (windstorms in 1999, heat wave in 2003, flooding for examples), Electricité de France created a research project untitled «EDF and climate change ». One objective of this project is to draw a map of high temperature risk by estimating the 100-year-return-period values in France. As a matter of fact, dimensioning of civil engineering works is based on statistical evaluation of return-levels for different meteorological parameters (wind speed, temperature, snow overloads for example) at defined returnperiods (20, 50 or 100 years, depending on the required reliability). For example, air conditioning for some sensitive industrial sites is based on 100-year-return-levels of high local temperature.

This statistical evaluation is based on the Extreme Value Theory (EVT hereafter), which exists since the mid- $20^{\text {th }}$ century, including two main families of methods. On the one hand, extreme events can be defined as maxima per given blocks of time (e.g. a year, a season or a month), described by the Generalized Extreme Value (GEV hereafter) distribution. On the other hand, in Peak-Over-Threshold (POT hereafter) method, extremes are retained values over a properly chosen high threshold. These exceedances, when independent and in sufficient quantity, follow a Generalized Pareto Distribution (GPD hereafter) and the series of time occurrences of these events follow a Poisson process. These methods were primarily introduced by Gumbel (1958). Leadbetter et al. (1983) give the detailed probabilistic foundations of the theory. Since, much advancement has been made in numerous fields such as in particular hydrology, meteorology or climatology (Tiago de Oliveira 1986, Buishand 1989, Farago and Katz 1990, Coles 2001).

These statistical methods are based on a stationary hypothesis, without any cycles nor trends in subseries of extremes. A trend since the late $19^{\text {th }}$ century in global averaged surface temperature is now admitted (Houghton et al. 2001) but concerning temperature extremes, no conclusion is given yet. In this climate change context, it is worth testing this hypothesis before using such methods. Indeed, for 
many industrial activities, estimation of extreme meteorological parameter (like temperature) in terms of a return-level in a non-stationary context becomes necessary to anticipate the future climatic evolution. Numerous studies are applied to climate change or climate variability in terms of meteorological extremes (Wigley 1988, Katz and Brown 1992, Brown and Katz 1995, Zwiers and Kharin 1998, Colombo et al. 1999, Katz 1999, Kharin and Zwiers 2000, Beniston 2004), but only a few investigate the potential non stationarity of these events (Frei and Schär 2001, Vogel et al. 2001, Katz et al. 2002 or Ramesh and Davison 2002 for hydrologic extremes, Benestad 2003 and 2004) and even less give solutions to calculate associated return-levels (Parey et al. 2005).

The aim of the present paper is to estimate from observations 100 -year-return-period temperatures in France in a non-stationary climate and compare them with the ones estimated in a hypothetic future climate at the end of the $21^{\text {st }}$ century, including different Intergovernmental Panel on Climatic Change (IPCC hereafter) scenarios of greenhouse gas concentrations evolution.

Two different kinds of data are then used in this study and are presented in Section 2: on the one hand, daily maximum temperatures measured at Météo-France available stations, and on the other hand, simulated temperatures in A2 and B2 IPCC scenarios conducted with the two French atmospheric models. As previously mentioned, to check the stationary hypothesis, a possible trend in observed extreme temperatures is first tested in a statistical way, to be then taken into account, if significant, in the extrapolation and estimation of a return-level using a POT method. Section 3 presents the methodology both for the statistical tests considering the trend in the parameters of the adjustment laws as a polynomial form (keeping the shape parameter constant), and for the return-levels estimations. The development of this methodology is described in more details in another paper, Parey et al. (2005), where a continuous piecewise linear form for trend was also tested and one conclusion of the paper was that a polynomial form for trend was a reasonable choice when series are relatively short. Finally in Section 4, results are given concerning both the statistical tests on observed trends and the extrapolation of observed climate compared to the values in future climate in terms of 100-yearreturn-period temperatures. Conclusion and discussion are given at the end of the paper. 


\section{Observed data and atmospheric simulations}

This work was partly conducted in the framework of a French research project named IMFREX (for «IMpact of the anthropogenic changes on the FRequency of the EXtreme phenomena of wind, temperature and precipitations », from April 2003 to April 2005) coordinated by Météo-France (Déqué et al. 2005). In the framework of this project, impacts of climate change on extremely high temperatures are studied. EDF R\&D, contributing to this project on this theme, can use both daily reference series (noted SQR in the following, for Séries Quotidiennes de Référence in French), which are the best and longest daily data available at Météo-France, and atmospheric simulations conducted with ARPEGE-Climat and LMDZ models by respectively Météo-France and CNRS/IPSL (PierreSimon Laplace Institute).

Indeed, SQR data are daily series of measures (temperature, precipitations and wind speed) for which a few criterions defined by Météo-France indicate, when they exceed associated thresholds, the date from which the series can be considered as relatively homogeneous. Among the $91 \mathrm{SQR}$ of daily maximum temperature available, 61 were firstly retained as being the closest to the grid points of the ARPEGE-Climat model. Lastly, 55 of these stations were studied in this paper, presenting sufficiently long series (at least 30 or 40 years) and without consecutive missing values (see Figure 1 for the geographical position and figure 2 for their beginning and ending years). The period of time retained for the detection of trend is 1960 to 2002, in coherence with the control period simulated by the models (from 1960 to 1999). As we will see in the following, some stations are considered from a more recent date, mainly from 1970 (and not 1960), because the trend becomes statistically significant from this period of time and not before. To consider an homogeneous population and because we are interested only in extremely high temperatures, SQR data are selected over the hot season. This season is defined here from June $14^{\text {th }}$ to September $21^{\text {st }}$, that is to say a 100 day-period. This choice arises 
from a study of monthly and weekly histograms for each station and seems to be reasonable to insure homogeneity in the data.

Both of the atmospheric models used are enabled to refine their grid over Europe by using their variable resolution version, to about $50 \mathrm{~km}$ over France for ARPEGE-Climat and around $150 \mathrm{~km}$ for LMDZ (see Figures 3 and 4 for ARPEGE-Climat and LMDZ grid points positions respectively). The resolution of LMDZ is then lower than ARPEGE-Climat.

For ARPEGE-Climat model, 3 ensembles of 3 climatic simulations are available in IMFREX project. The first ensemble consists of 3 simulations of present climate over 40 years, between 1960 and 1999 , with sea-surface temperature observed over this period as limit conditions. The two other ensembles consist each one of 3 30-year-simulations of a possible future climate, between 2070 and 2099, according to 2 IPCC assumptions of greenhouse gas concentrations evolution (reference numbers A2 and B2 scenarios). The scenario are described in Albritton et al. (2001). The A2 scenario describes a very heterogeneous world, with a continuously increasing population and slow and fragmented economic growth and technological change. The B2 scenario describes a world in which the emphasis is on local solutions to economic, social and environmental sustainability. It is a world with continuously increasing global population, at a lower rate than A2, intermediate levels of economic development, and less rapid and more diverse technological change than in the B1 and A1 storylines. The first ensemble uses a B2 scenario for greenhouse gas concentrations evolution, the other one a A2 type scenario (which is a more pessimistic scenario than B2 scenario, as described above). Sea-surface temperatures are the ones observed between 1960 and 1989 for which the difference between temperatures simulated for an end of century climate and temperatures simulated for actual climate with the Hadley Centre coupled model (for transient simulations with the same scenario) is added.

For LMDZ model, 3 simulations are available: one simulation of present climate with identical seasurface temperatures each year, equal to the mean of the sea-surface temperatures observed over the 1979-1999 period (this corresponds to a climatological mode). The two other simulations are future climate simulations (around year 2085) with mean sea-surface temperatures reconstructed from observations to which are added the mean differences respectively calculated by the IPSL coupled 
model on the one hand, and the ARPEGE-Climat/OPA coupled model on the other hand, during a transient simulation with a A2 scenario of greenhouse gas concentrations evolution.

For model analysis, the sub-series are extracted over whole months in summer, over June-JulyAugust-September months, noted JJAS in the following. In the present climate simulations, a correction is applied at each grid point on distributions of JJAS temperatures classified by percentiles to correspond to the nearest observations distributions. The same intensity of correction is then applied to the summer temperature distributions from the future climate simulations (see Appendix 1 for details)

\section{Methodology}

\subsection{Detection of observed trends}

The first step of the process is to study the possible presence of trends in SQR high temperatures. The statistical treatment applied to the sub-series varies according to the extreme values method used. As mentioned in the introduction, two different methods exist in the EVT: the block maxima method and the Peak-Over-Threshold method. For each, the statistical test used for a polynomial trend detection is described. This first step will allow to conclude on the presence (or not) of a significant trend in each SQR high values series, and to choose the optimal model for polynomial trends at each station.

In the block-maxima method, we retain the degree of polynomial trend in the parameters of the GEV distribution (the position parameter $\mu(\mathrm{t})$ and the scale parameter $\sigma(\mathrm{t})$; the shape parameter $\xi$ staying constant), which, on the one hand, defines a trend that describes the best the observed series of extremes and, on the other hand, can be extrapolated (that means to choose a monotonous trend). To do so, Chi2 tests on the likelihood of nested models, with increasing degrees for $\mu(t)$ and $\sigma(t)$, are realized following the theorem from Coles (2001). 
If $\mathrm{M}_{0}$ with parameter $\theta^{(2)}$ is the sub-model of $\mathrm{M}_{1}$ with parameter $\theta_{0}=\left(\theta^{(1)}, \theta^{(2)}\right)$ under the constraint that the k-dimensional sub-vector $\theta^{(1)}=0$, and $l_{0}\left(\mathrm{M}_{0}\right)$ and $\mathrm{l}_{1}\left(\mathrm{M}_{1}\right)$ are the maximized values of the loglikelihood for models $\mathrm{M}_{0}$ and $\mathrm{M}_{1}$ respectively, then a test of the validity of model $\mathrm{M}_{0}$ relative to $\mathrm{M}_{1}$ at the $\alpha$ significance level consists in rejecting $\mathrm{M}_{0}$ in favour of $\mathrm{M}_{1}$ if:

$2\left\{1_{1}\left(M_{1}\right)-1_{0}\left(M_{0}\right)\right\}>c_{\alpha}$, where $c_{\alpha}$ is the $(1-\alpha)$ percentile of the $\chi_{k}^{2}$ distribution.

In the present study, each series comprises 4 blocks per year, because the summer season lasts 100 days and a block is taken as 25 days. A linear model in $\mu(t)$ with constant $\sigma$ (this model is noted $(1,0)$ in the following, corresponding to the degree of $\mu$ and the degree of $\sigma$ in parenthesis) is compared to a stationary model both for $\mu$ and $\sigma$ (noted $(0,0)$ with previous notations) and also with more complicated models (noted $(1,1)$ or $(2,0)$ with previous notations). In fact, we look for a model with the simplest trend, which corresponds to a linear trend in the position parameter (corresponding, in a first approximation, to the mean of the extremes). Two levels of significance are tested : $90 \%$ and $95 \%$.

In the POT method, a temporal trend in the scale parameter of the GPD (noted $\sigma(\mathrm{t})$, corresponding to level reached over the threshold) and in the intensity of the Poisson process (noted I(t), corresponding to the frequency of threshold exceedances) are studied. For these two parameters, the same kind of likelihood tests as for GEV parameters are conducted at the $90 \%$ and $95 \%$ significance levels. In the present study, after having checked that the choice of threshold is reasonable according to the tests defined by Coles (2001), the threshold for each series is defined by keeping $3 \%$ of the "declusterised" summer series (corresponding to $1 \%$ of the total series), that is to say about 150 "declusterised" values above the threshold. Indeed, inside a cluster (defined by consecutive daily values above the threshold), only the maximum value is kept to check the independence hypothesis of data : this step corresponds to a "declustering" procedure (see Coles 2001). As for the block maxima method, we look for a model with the simplest trend to be in a second time extrapolated to estimate a 100 -year-return-period temperature. For this reason, only the tests of linear and quadratic models in $\sigma(t)$ and $I(t)$ are conducted in the following. 


\subsection{Estimation of a 100-year-return-period temperature}

The second step of the process is to estimate a 100-year-return-period temperature both in extrapolated present climate and in simulated future climate. Two approaches are then compared.

The first approach corresponds to a non-stationary (or stationary) extrapolation of the present climate from the studied period, depending on the significance (or not) of the trends. This present climate is observed via the SQR (mainly from the 1960s or 1970s). The present climate simulations are not used for extrapolations because a correction towards the observations in terms of distributions was applied and so they will not give any complementary information. This step of correction is however necessary to correct future climate scenarios from this model bias (see Appendix 1). In cases where trend in observed data is statistically significant, a non-stationary extrapolation of extremes is applied using the POT method (GEV extrapolation could also be used in the same way, but interpretation of the results is more physical with POT method). As a reminder (see Coles 2001 and Parey et al. 2005 for more details), in POT method, the series of dates of exceedances follow a Poisson process of intensity I and the series of exceedances values (over a threshold noted u) follow a GPD, whose cumulative distribution function is

$$
\begin{aligned}
& P(x<X / X>u)=\left[1+\frac{\xi}{\sigma}(x-u)\right]^{-\frac{1}{\xi}} \text { if } \xi \neq 0, \text { and } \\
& P(x<X / X>u)=\exp \left(-\frac{x-u}{\sigma}\right) \text { otherwise }
\end{aligned}
$$

where $\sigma$ is the scale parameter and $\xi$ the shape parameter

In non-stationary cases, as previously described, one supposes that $\sigma$ and I vary with time, and $\xi$ is supposed to be constant (according to classical practice, see Coles 2001). The return-level (noted z) for a period of future time (noted a) is defined in such a way that the probability of exceeding $\mathrm{z}$ during a is, on average, equal to one. Unlike under stationary condition, the 100-year return level, for example, can no more be seen as a value exceeded with a mean probability of $1 / 100$ each year. It is 
here defined as a value reached or exceeded in expectation 1 day over the hot season days of the next 100 years. The following expression is then numerically optimized to find $\mathrm{z}$ :

$$
\begin{gathered}
\sum_{t=1}^{a}\left(P\left(X_{t}>z / X_{t}>u\right) * P\left(X_{t}>u\right)\right)=1 \\
\text { or } \sum_{t=1}^{a}(G P D(z, t) * I(t) * \exp (-I(t)))=1
\end{gathered}
$$

where $\operatorname{GPD}(\mathrm{z}, \mathrm{t})$ represents the Generalized Pareto cumulative distribution function.

The second approach consists in directly using the climate change scenarios simulated by the models, A2 and B2 scenarios for ARPEGE-Climat and A2 scenario for LMDZ, to estimate a 100-year-returnlevel temperature in stationary conditions. An estimation under stationary conditions is chosen even if ARPEGE-Climat model uses evolving sea-surface temperatures and greenhouse gas concentration in the simulations. Some trend identifications conducted on these model results showed that the simulated trends are not realistic, mainly because sea-surface temperature evolutions are not homogeneous over time and space. Furthermore, this assumption makes the evaluations from each of the two models comparable.

As previously mentionned, these scenarios were also corrected over the summer season of the same existing variation in temperature as the one existing between the simulated present climate and the

observed climate (see Appendix 1). The centennial return-level is then estimated in stationary conditions according to the POT method, by keeping 80 "declusterised" values above the threshold at each grid point (corresponding to the same rule for threshold definition than for observations).

\section{Results}

\subsection{Trends in SQR}

With the block maxima method, a model $(1,0)$ (corresponding, with previous notations, to a linear model for $\mu(\mathrm{t})$ and a stationary model for $\sigma(\mathrm{t})$ ) is more significant (at $90 \%$ and $95 \%$ levels) than the 
$(1,1)$ model for $98 \%$ of the SQR studied. This model $(1,0)$ is also more significant (at $90 \%$ and $95 \%$ levels) than the $(2,0)$ model for $91 \%$ of cases. With the POT method, a quadratic model for $\mathrm{I}(\mathrm{t})$ and a stationary model for $\sigma$ seem to be the optimal models for the majority of the SQR studied. These results are summarized in Table 1 in the following way :

- Block maxima method: Test of a linear model for $\mu(\mathrm{t})$ and a stationary $\sigma$ (noted $(1,0)$ ) compared with a stationary model (noted $(0,0)$ ) at a $90 \%$ confidence level: column 1 of the table

- Block maxima method: Test of a linear model for $\mu(\mathrm{t})$ and a stationary $\sigma$ (noted $(1,0)$ ) compared with a stationary model (noted $(0,0)$ ) at a $95 \%$ confidence level: column 2 of the table

- POT method: Test of a quadratic model for $\mathrm{I}(\mathrm{t})$ compared with a stationary model at a 90 and 95\% confidence level (columns 3 and 4 ) and test of a stationary model for $\sigma(t)$ compared with models of superior degree (at least linear, at a 90 and 95\% confidence level) in column 5 and 6 of the table.

Results are the following, for each extreme values method tested :

- block maxima method: a linear trend on $\mu(\mathrm{t})$ is observed from the 1960s or 1970s, which is more significant than a stationary evolution (at $90 \%$ and/or $95 \%$ levels). This result is verified for $78 \%$ of the studied SQR.

- POT method: a generally quadratic increase of the frequency of the exceedances of extremely high temperatures over the threshold is observed from the 1960s or 1970s, but keeping a stationary amplitude of these exceedances. These results are verified respectively for $93 \%$ and 94\% of the studied SQR.

An example of these results is given in Figures 5 and 6 for Orange station. Figure 5 shows a temporal evolution of maximum temperature per 25-day block (over the period 1960-2002) as a function of the number of blocks, during the summer season, that is to say 4 extremes per season (and per year). The 
linear evolution of $\mu(\mathrm{t})$, estimated with a maximum likelihood method and represented as a straight line on the Figure, is statistically significant. In POT method, the threshold retained for Orange is $33,7^{\circ} \mathrm{C}$, corresponding to 150 declusterised temperatures above this threshold over the period 1960 to 2002. Figure 6 represents the evolution of temperatures above this threshold as a function of dates of exceedances, during the summer season. On the one hand, the evolution of the intensity of the exceedances stays stationary in a statistical point of view. On the other hand, the frequency of the exceedances follows a quadratic evolution with time.

Among available SQR, some cover a relatively long period of measures (like Paris-14eme for example, starting on the $1^{\text {st }}$ January of 1915). In the present study, trend in extremely high temperatures is sometimes significant only in the last decades (typically from the 1960s or 1970s). So, considering the whole series can sometimes hide this end-of- $20^{\text {th }}$ century trend in terms of statistical tests. This is the case for Paris-14eme where the test for a linear $\mu(\mathrm{t})$ compared to a stationary one is not significant over the total period (1915-2002, that is to say 88 years), significant at $90 \%$ level over the 1950-2002 period (that is to say 53 years), and significant at 95\% levels over the 1970-2002 period (that is to say 33 years). The same conclusion is established for POT method. The dependence of the trend significance as a function of the observation period is discussed in more details in Parey et al. (2005). If $\mathrm{CO}_{2}$ concentration is considered as covariate instead of time, the identified trends are the same. Thus, the evolution with time mimics the evolution with increasing $\mathrm{CO}_{2}$ concentration. Therefore, based on a great number of temperature series in France, it can be considered that the identified trend in the last part of $20^{\text {th }}$ century is reasonably representative of the ongoing human induced climate change and may be extrapolated to estimate future behaviour. Of course, this extrapolation must not be taken as a prevision but rather as an indication. As trend are closely linked to the sample considered, updates will have to be made regularly as far as observed series become longer. 


\subsection{0-year-return-period temperatures}

\subsubsection{SQR}

Because POT method allows a more physical interpretation of the results than the block maxima method by using two independent parameters, only extrapolations based on this method are calculated in the present study. The parameters of the distributions are estimated with a maximum likelihood method (see Coles 2001).

Figure 7 shows the 100-year-return-period temperatures (noted T100 hereafter) obtained by a nonstationary extrapolation of SQR from 1960 to 1999 with a temporal trend following a stationary model for $\sigma(t)$ and a quadratic model for I(t) (noted OBS02 in the following), which is the significant observed trend for most of SQR (see previous part). Temperature values are corrected to the nearest whole number at each studied station. Centennial temperatures superior or equal to $40^{\circ} \mathrm{C}$ are mainly located southward of a line joining Augny station in the north-east to La Rochelle station on the west coast. A station in the Massif Central indicates a value of only $29^{\circ} \mathrm{C}$. Indeed, it corresponds to Valleraugue station, located on the Mont-Aigoual (at an altitude of 1567 metres), hence a colder temperature than around. This value can be corrected from this altitude effect (using the standard atmosphere gradient of $\left.6.5^{\circ} \mathrm{C} / \mathrm{km}\right)$, to obtain a temperature of $39.2^{\circ} \mathrm{C}$.

As an indication and because some stations indicate a linear evolution for $\sigma(\mathrm{t})$, the same kind of figure as Figure 7 is given in Appendix 2 (on Figure 8) with a temporal trend following a linear model for $\sigma(t)$ and a quadratic model for I(t) (noted OBS12 in the following). Even if this model of trend is not yet significant for the majority of the stations, temperatures are, in this case and in a logical way, higher in places where the trend on $\sigma(\mathrm{t})$ is increasing, and overall the $\mathrm{T} 100 \geq 40^{\circ} \mathrm{C}$ zone extends a little more to the north (with Le Mans, Bricy, Lesquin stations, for example, exceeding this value).

Because 2003 was a hotter summer than usual in France, this year (which was not included yet in the SQR data) was considered. The same extrapolation as in Figure 7 is then calculated for SQR from 1960 to 2003 (adding the period 2000-2003 to previous observations)-see Figure 9. Only two stations 
can not be used because the JJAS season for 2003 was not available for one, and the optimisation function for the return-level calculation did not give a result for the other (due to the positive sign of the GPD shape parameter $\xi$, equal to 0.02 , which is not correct and induces a not limited distribution). Results from 1960 to 2003 are either identical either slightly above the ones calculated from 19601999 (Figure 7). In particular, the $\mathrm{T} 100 \geq 40^{\circ} \mathrm{C}$ zone is more extended to the north (Saint-Jacques de la Lande and Courcy stations for example indicating centennial temperatures above $40^{\circ} \mathrm{C}$ ). As previously, Appendix 2 (on Figure 10) presents the results for OBS12 on the same extended time period (1960-2003). The T100 $\geq 40^{\circ} \mathrm{C}$ zone is then almost extended to the whole France, except for 2 stations in the south (Valleraugue being at a higher altitude, and Sète) and 3 stations on the northern coast (Dunkerque, Boulogne-sur-mer and Sainte-Adresse).

\subsubsection{Climatic simulations}

100-year-return-period temperatures are also estimated, but in stationary conditions, from climatic simulations of the end of $21^{\text {st }}$ century. ARPEGE-Climat uses evolving forcings for greenhause gas concentrations and sea surface temperature, so a similar trend identification could have been used. However, the tests made showed that the trend in simulated extremes are not really coherent with observed trends in present climate conditions, mainly because evolving forcing are not homogeneously imposed (Mediterranean sea for example has mean conditions each year). Therefore, and for coherence between the 2 models, we choose to estimate return levels under stationary conditions here. T100 are estimated from ARPEGE-Climat model in A2 and B2 scenarios (see Figures 11 and 12 respectively), and from LMDZ model in A2 scenario (see Figure 13).

In Figure 11, the $\mathrm{T} 100 \geq 40^{\circ} \mathrm{C}$ zone is extended to the whole country, except for 3 grid points located in the French Alps. Indeed, these grid points are located at a higher altitude than around, at about 1900 metres, corresponding to a temperature correction of approximately $12^{\circ} \mathrm{C}$ to bring these points back to the sea level. After correction of this altitude effect, T100 of this area also exceeds $40^{\circ} \mathrm{C}$.

In Figure 12, corresponding to a B2 scenario, T100 are less hot than the ones corresponding to a A2 scenario, in accordance with what is expected, because B2 scenario is less pessimistic than $\mathrm{A} 2$ one in 
terms of carbon dioxide concentration evolution. In particular, 10 grid points are concerned with T100 lower than $40^{\circ} \mathrm{C}$, located in the Alps (for 8 of them), in the eastern Pyrenees (one grid point at an altitude of 1441 metres, which corresponds to a temperature correction due to altitude effect of $9^{\circ} \mathrm{C}$ to bring this point back to the sea level) and in the Massif Central (one grid point at an altitude of 866 metres corresponding to a temperature correction of about $\left.5.6^{\circ} \mathrm{C}\right)$. All of these 10 points correspond to points with an altitude higher than surroundings.

Figure 13 corresponds to the T100 for LMDZ model (with a A2 scenario). We can see that the spatial resolution of LMDZ is coarser than the one of ARPEGE-Climat. One can observe however that, like in observations, a few grid points are concerned with temperatures lower than $40^{\circ} \mathrm{C}$ (they are located in the north-west and in the south for one point). T100 estimated from LMDZ model are close to the T100 estimated from OBS12 on 1960-2003, corresponding with previous notations to a linear model for $\sigma(t)$ and a quadratic model for I(t) (see Figure 10 in Appendix for reminder).

These results indicate that observations extrapolated in non-stationary conditions with a significant present trend indicate centennial temperatures of an order of magnitude comparable to the ones from LMDZ model (with a A2 scenario). ARPEGE-Climat model seems to be hotter than LMDZ model concerning the estimated 100-year-return-period temperatures. Indeed, B2 scenario with ARPEGEClimat model gives for most grid points hotter T100 than A2 scenario with LMDZ model, even if B2 scenario is based on more optimistic hypothesis concerning carbon dioxide concentration evolution than A2 scenario. It must be mentioned however that the distribution correction applied may play a role. For some grid points, the applied correction enhances ARPEGE-Climat behaviour under future climate conditions : as a matter of fact, ARPEGE-Climat tends to enhance standard deviation in future climate, leading to much more high temperature values. As on the contrary, in present day climate, the model simulates a too narrow distribution, correction enhances again the standard deviation, probably leading artificially to higher extremes. 


\section{Conclusion and Discussion}

A study of a possible temporal trend in 55 daily maximum temperatures stations (from Météo-France) gives the following conclusions :

- a significant linear trend is observed in maxima per 25-day blocks in summer season over the period from 1960 (or 1970, depending on the stations) to nowadays

- when not considering a regular sampling as with blocks of time but a threshold (varying according to the station), a quadratic increase of the frequency of threshold exceedances is observed from the 1960s or 1970s, but keeping a stationary amplitude. This result means that temperatures exceeding the threshold are more frequent nowadays than 30 or 40 years ago, but with similar amplitudes.

The POT method does not take into account the length of the high temperature events because the theory assumes that values above the threshold must stay independent. By keeping only the maximum value inside a cluster of consecutive daily values above the threshold (which is a "declustering" procedure), some information is thus consciously lost. Keeping the information on the length of the clusters in addition to their intensity should be an interesting improvement of the POT method.

Concerning an estimation of the daily maximum air temperature for a chosen return-period (here 100 years), two approaches are compared in the present study. The simple extrapolation of the observed significant trends (mainly over 1960 to 1999 ) does not allow to reach the levels of the end of $21^{\text {st }}$ century simulated by ARPEGE-Climat on the one hand, but on the other hand, it gives orders of magnitude closer (but lower) to LMDZ results. Adding the period from 2000 to 2003 (including the heat wave on August 2003 in France) to previous observations slightly increases the centennial temperatures in some areas of France. When an increasing trend exists in the scale parameter of the GPD, even if it is not yet significant (for example in the south of France), taking it into account makes it possible to reach the levels of the end of $21^{\text {st }}$ century of ARPEGE-Climat (both A2 and B2 types 
scenarios). In a possible future climate, ARPEGE-Climat and LMDZ scenarios simulate a range of centennial temperatures which seem to be higher compared to actual estimations. One must however keep in mind that the correction method used tends to quite artificially enhance extremes evaluated from ARPEGE-Climat model. Many improvements of this study could be envisaged. Firstly, it could be interesting to compare simulated trends in extremes with observed ones, in using transient climate simulations for the $20^{\text {th }}$ century. This could learn on how realistically models can simulate extremes. Secondly, the role of bias correction should be more carefully studied in order to better understand the differences between models, and between extreme levels evaluated from observed trend extrapolation and from model simulations. Finally, in the actual climate change context, extrapolation of the present trends should be limited to the next few years, and the future evolution has to be confirmed beyond, by again studying the shape of the tendency of the extremely high temperatures in the next few years. 


\section{Acknowledgements}

Authors would like to thank Michel Déqué (from Météo-France) and collaborators of the IMFREX research project for constructive exchanges during the life time of the project, and Météo-France and IPSL for SQR data and climatic simulations supplying, as well as Professor Didier Dacunha-Castelle (from the Laboratoire de Mathématiques de l'Université d'Orsay) for the development of trend identification in extreme values and his kind help in using the statistical extreme value theory.

\section{Appendices}

\subsection{Appendix 1 : Correction of the simulated distributions compared to the observed distributions}

Climate models represent fairly well the mean climate characteristics but may show some biases at the local scale. As we intend here to compute 100 -year return levels at individual grid points, we chose to firstly correct the summer temperature distribution of the grid point in the present day climate to let it fit the nearest observed distribution. In order to do so, we compute each percentile of the observed and simulated summer temperature distributions. Then, each daily value in the simulated series is ordered between two successive percentiles and corrected to a value placed in the same position in the observed percentile distribution. So, the 2 distributions coincide and we could verify that the 100 -year return levels, estimated in stationary conditions, are coherent between observations and simulations for present day climate. Then, the same intensity of correction is applied to future climate simulation summer temperature distributions. This implies then that we suppose the biases as unchanged in the future.

\subsection{Appendix 2 : Figures of T100 for OBS12 (from 1960-1999 and 1960-2003)}

Figures 8 and 10 here 


\section{References}

Albritton, D.L., Allen, M.R., Baede, A.P.M., Church, J.A., Cubasch, U., Xiaosu, D., Yihui, D., Ehhalt, D.H., Folland, C.K., Giorgi, F., Gregory, J.M., Griggs, D.J., Haywood, J.M., Hewitson, B., Houghton, J.T., House, J.I., Hulme, M., Isaksen, I., Jaramillo, V.J., Jayaraman, A., Johnson, C.A., Joos, F., Joussaume, S., Karl, T., Karoly, D.J., Kheshgi, H.S., Le Quéré, C., Maskell, K., Mata, L.J., McAvaney, B.J., McFarland, M., O. Mearns, L.O., Meehl, G.A., Meira-Filho, L.G., Meleshko, V.P., Mitchell, J.F.B., Moore, B., Mugara, R.K., Noguer, M., Nyenzi, B.S., Oppenheimer, M., Penner, J.E., Pollonais, S., Prather, M., Prentice, I.C., Ramaswamy, V., Ramirez-Rojas, A., Raper, S.C.B., Salinger, M.J., Scholes, R.J., Solomon, S., Stocker, T.F., Stone, J.M.R., Stouffer, R.J., Trenberth, K.E., Wang, M.-X., Watson, R.T., Yap, K.S., Zillman, J., with contributions from many authors and reviewers, 2001. Summary for Policymakers. A Report of Working Group I of the Intergovernmental Panel on Climate Change.

Benestad, R.E., 2003. How often can we expect a record-event? Climate Research 25, 3-13.

Benestad, R.E., 2004. Record-values, nonstationarity tests and extreme value distributions. Global and Planetary Change 44, 11-26.

Beniston, M., Stephenson, D.B., 2004. Extreme climatic events and their evolution under changing climatic conditions. Global and Planetary Change 44, 1-9.

Brown, B.G., Katz, R.W., 1995. Regional Analysis of extremes: spatial analog for climate change ? J.Climate 8, 108-119.

Buishand, T.A., 1989. Statistics of extremes in climatology. Statistica Neerlandica 43, 1-30. 
Colombo, A.F., Etkin, D., Karney, B.W., 1999. Climate variability and the frequency of extreme temperature events for nine sites across Canada: implications for power usage. J.Climate 12, 24902502.

Coles, S.G., 2001. An Introduction to Statistical Modeling of Extreme Values. Springer Series in Statistics, London.

Déqué et al. (to be completed), 2005. Impacts des changements anthropiques sur la fréquence des phénomènes extrêmes de vent, de température et de précipitations (IMFREX). Final GICC (Gestion et Impacts du Changement Climatique) French report submitted to a scientific committee.

Farago, T., Katz, R.W., 1990. Extremes and design values in climatology. Report No.WCAP-14, WMO/TD-No.386, World Meteorological Organization, Geneva.

Frei, C., Schär, C., 2001. Detection probability of trends in rare events: Theory and application to heavy precipitation in the Alpine region. J.Climate 14, 1568-1584.

Gumbel, E.J., 1958. Statistics of extremes. Columbia University Press, New York, 375pp.

Houghton, J.T., Ding, Y., Griggs, D.J., Noguer, M., van der Linden, P.J., Dai, X., Maskell, K., Johnson, C.A., 2001. Climate change 2001: the scientific basis. Contribution of Working Group I to the Third Assessment Report of IPCC. International Panel on Climate Change, Available from www.ipcc.ch.

Katz, R.W., 1999. Extreme value theory for precipitation: sensitivity analysis for climate change. Advances in Water Resources 23, 133-139. 
Katz, R.W., Brown, B.G., 1992. Extreme events in a changing climate: variability is more important than averages. Climatic Change 21, 289-302.

Katz, R.W., Parlange, M.B., Naveau ,P., 2002. Statistics of extremes in hydrology. Advances in Water ressources 25, 1287-1304.

Kharin, V.V., Zwiers, F.W., 2000. Changes in the extremes in an ensemble of transient climate simulations with a coupled Atmosphere-Ocean GCM. J.Climate 13, 3760-3788.

Leadbetter, M.R., Lindgren, G., Rootzen, H., 1983. Extremes and related properties of random sequences and series. Springer Verlag, New York.

Parey, S., Malek, F., Laurent, C., Dacunha-Castelle, D., 2005. Trends and climate evolution : statistical approach for very high temperatures in France. Submitted to Climatic Change.

Ramesh N.I., Davison A.C., 2002. Local models for exploratory analysis of hydrological extremes. J Hydrol 256,106-19.

Tiago de Oliveira, J., 1986. Extreme values and Meteorology. Theor.Appl.Climatol. 37, 184-193.

Vogel, R.M., Zafirakou-Koulouris, A., Matalas, N.C., 2001. The frequency of record breaking floods in the United States. Water Resources Research 37, 1723-1731.

Wigley, T.M.L., 1988. The effect of changing climate on the frequency of absolute extreme events. Climate Monitor 17, 44-55.

Zwiers, F.W., Kharin, V.V., 1998. Changes in the extremes of the climate simulated by CC GCM2 under CO2 doubling. J.Climate 11, 2200-2222. 


\section{Tables and table captions}

\begin{tabular}{|l|c|c|c|c|c|}
\hline \multicolumn{2}{|c|}{ Block maxima method : number of series with } & \multicolumn{4}{c|}{ POT method : number of series with } \\
significant trends & \multicolumn{4}{c|}{ significant trends } \\
\hline Linear $\mu(\mathbf{t})$ and & Linear $\mu(\mathbf{t})$ and & Quadratic & Quadratic & Stationary & Stationary \\
stationary $\sigma: 90 \%$ & stationary $\sigma: \mathbf{9 5 \%}$ & I(t) : 90\% & I(t) : 95\% & $\sigma:$ 90\% & $\sigma: 95 \%$ \\
significant level & significant level & significant & significant & significant & significant \\
& & level & level & level & level \\
\hline 43 & 39 & 51 & 49 & 44 & 52 \\
\hline
\end{tabular}

Table 1. Results of the tests of significance : number of series with significant trends with the block maxima method (linear $\mu(t)$ and stationary $\sigma$ with a $90 \%$-first column- and $95 \%$-second columnsignificance level) and with the POT method (trends on I(t) with $90 \%$ and $95 \%$ significance level and trends for $\sigma$ with the same confidence levels). 


\section{Figures and figure captions}

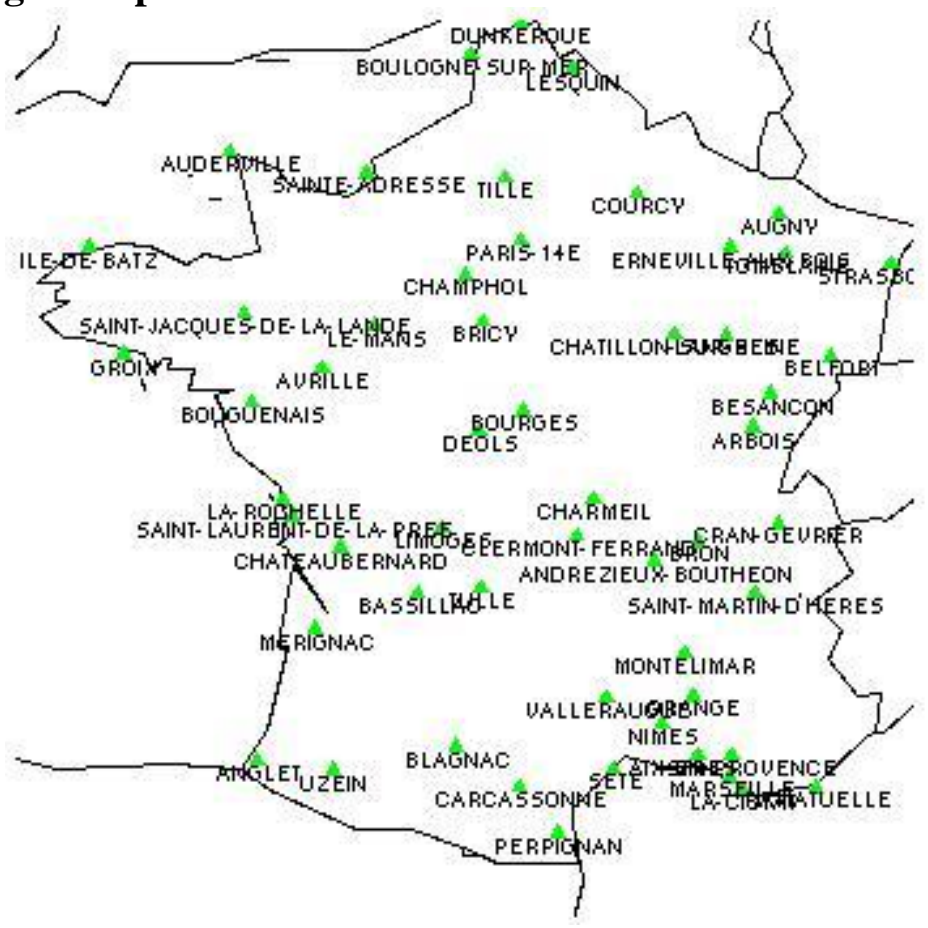

Figure 1

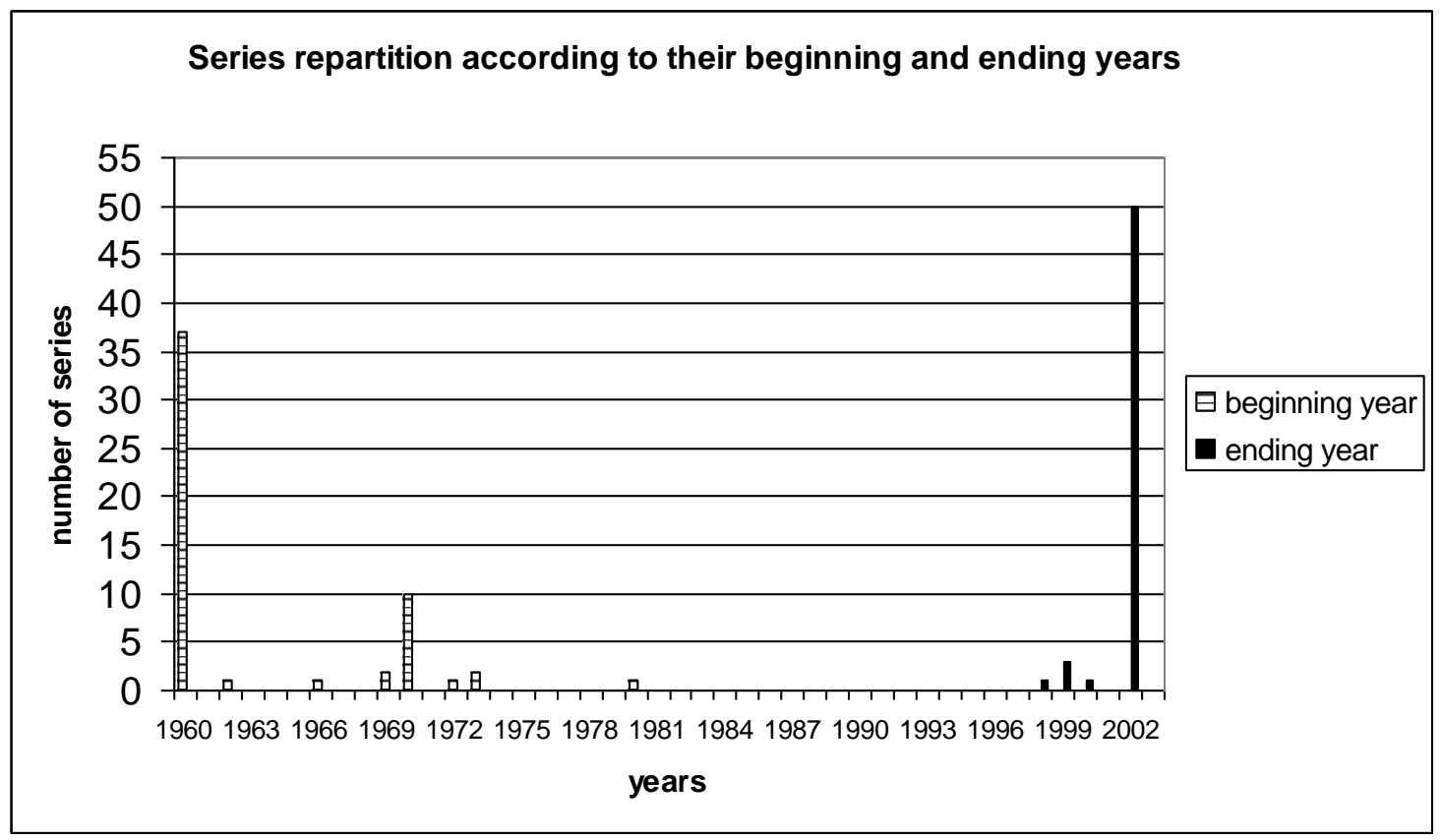

Figure 2 


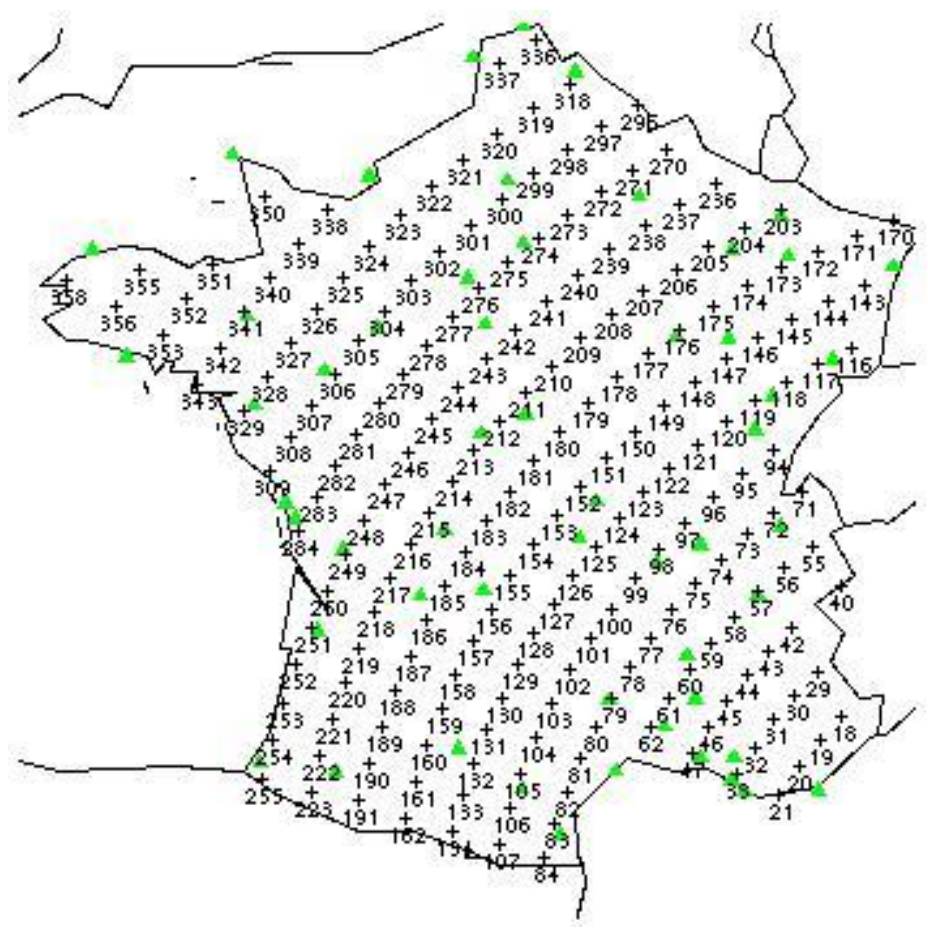

Figure 3

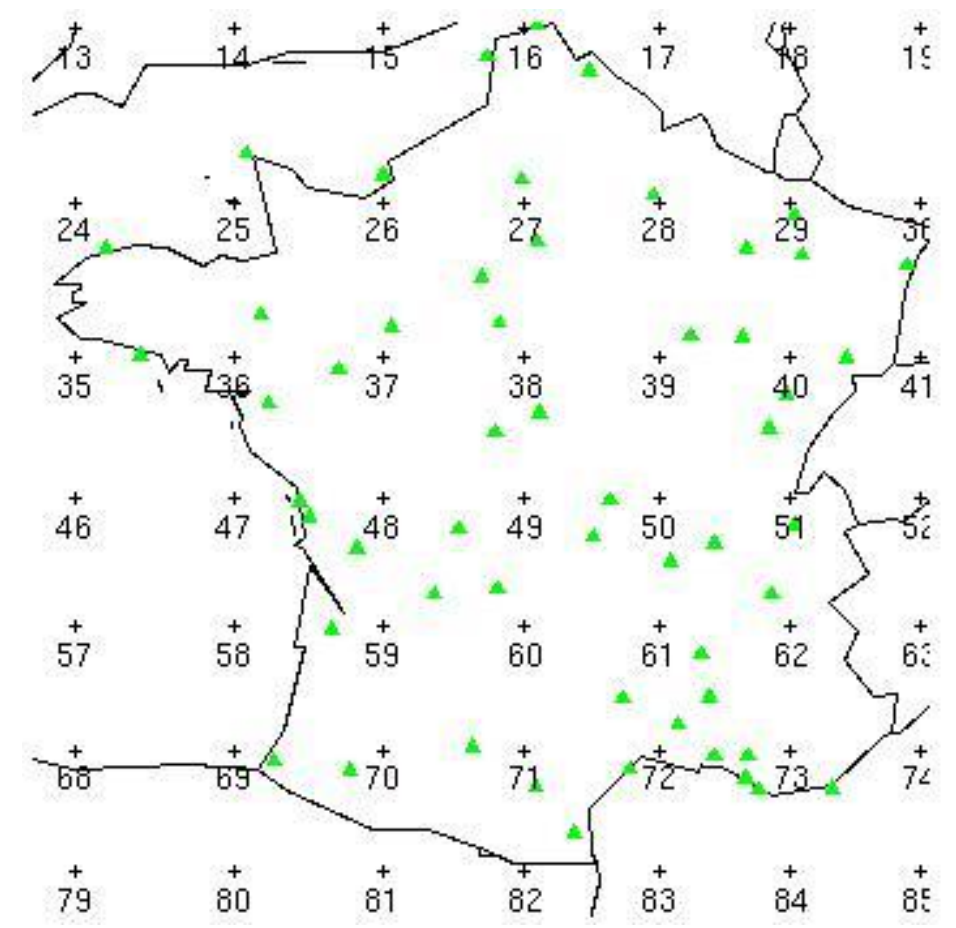

Figure 4 


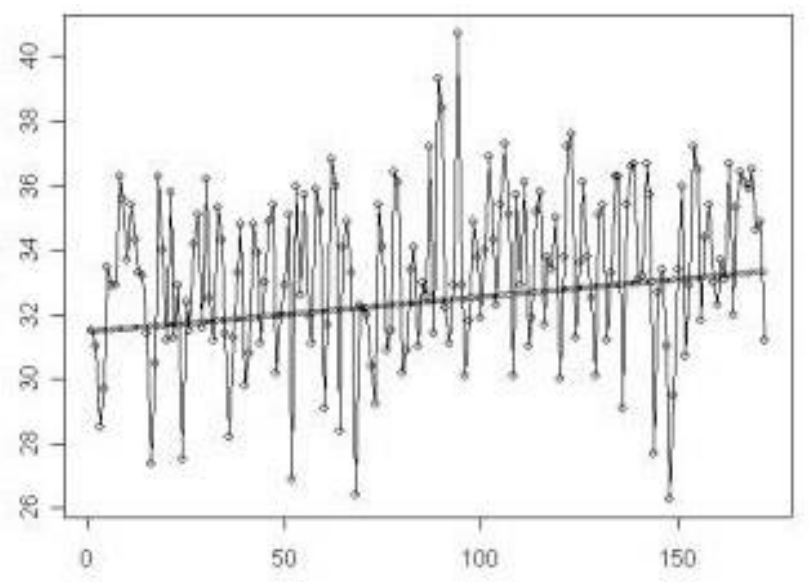

Figure 5

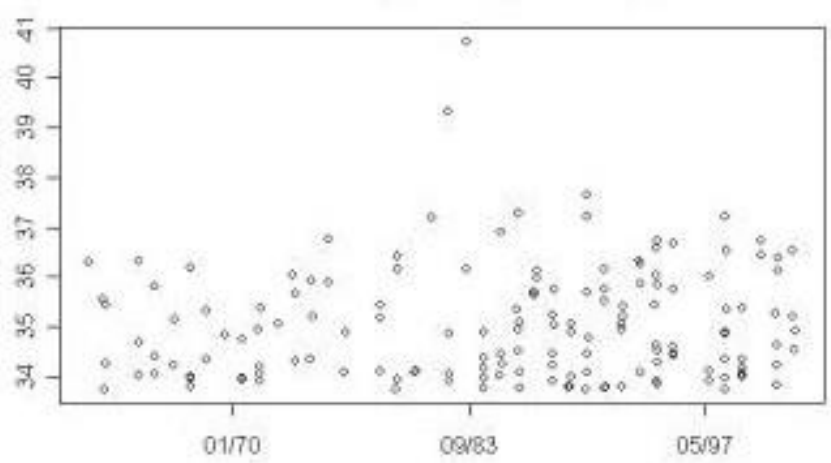

Figure 6

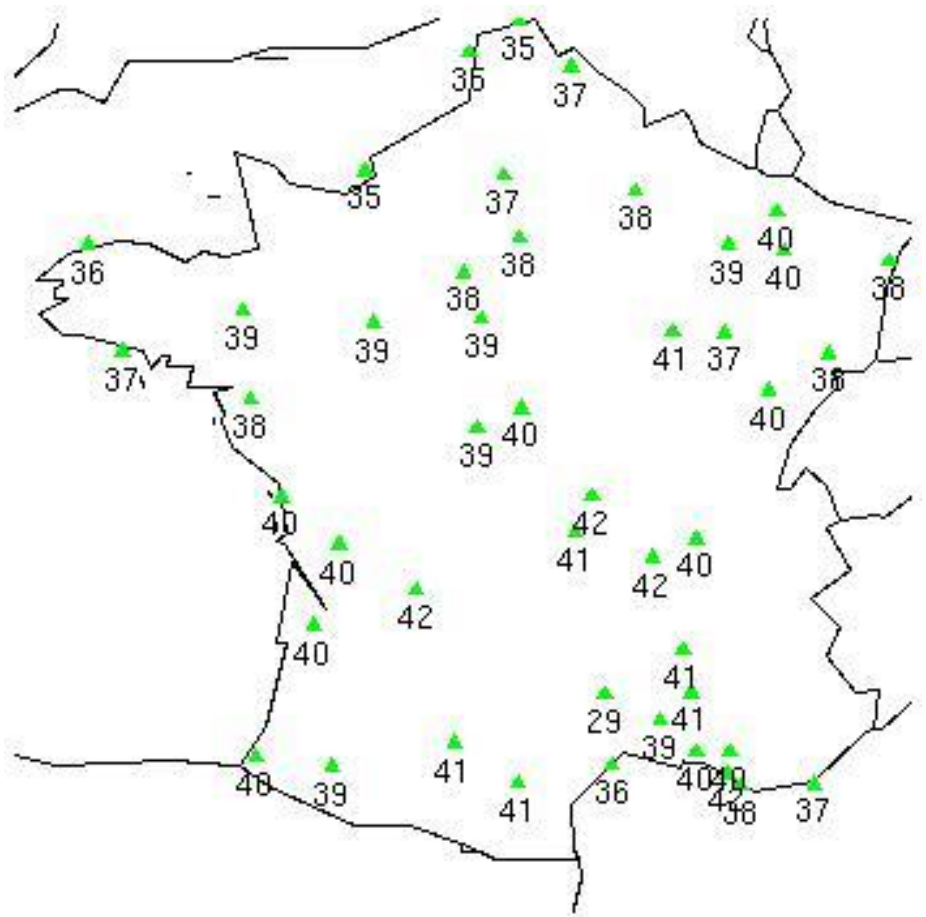

Figure 7 


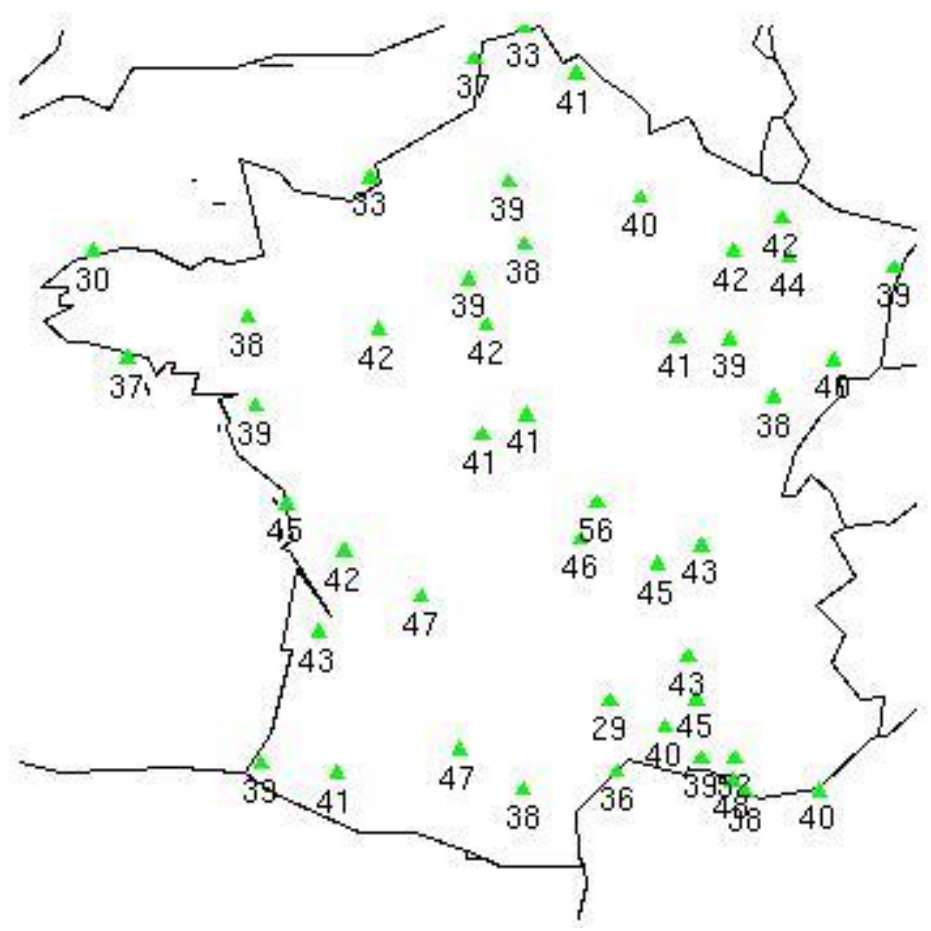

Figure 8 (Appendix 2)

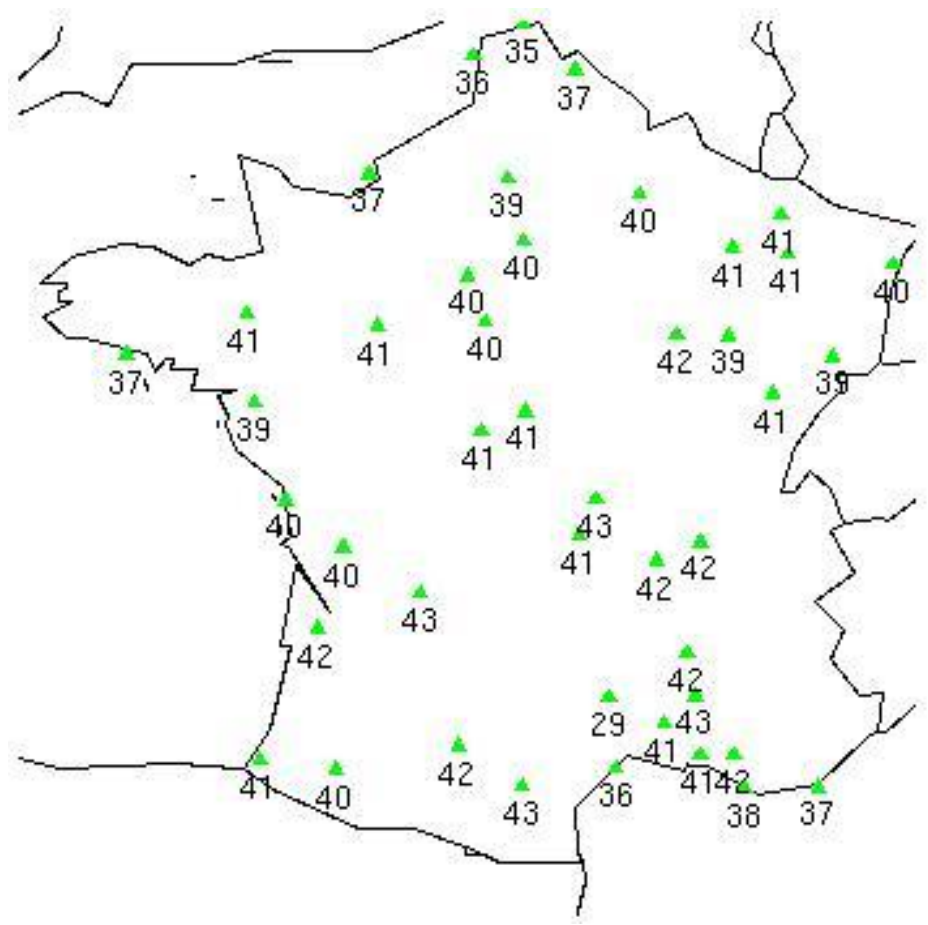

Figure 9 


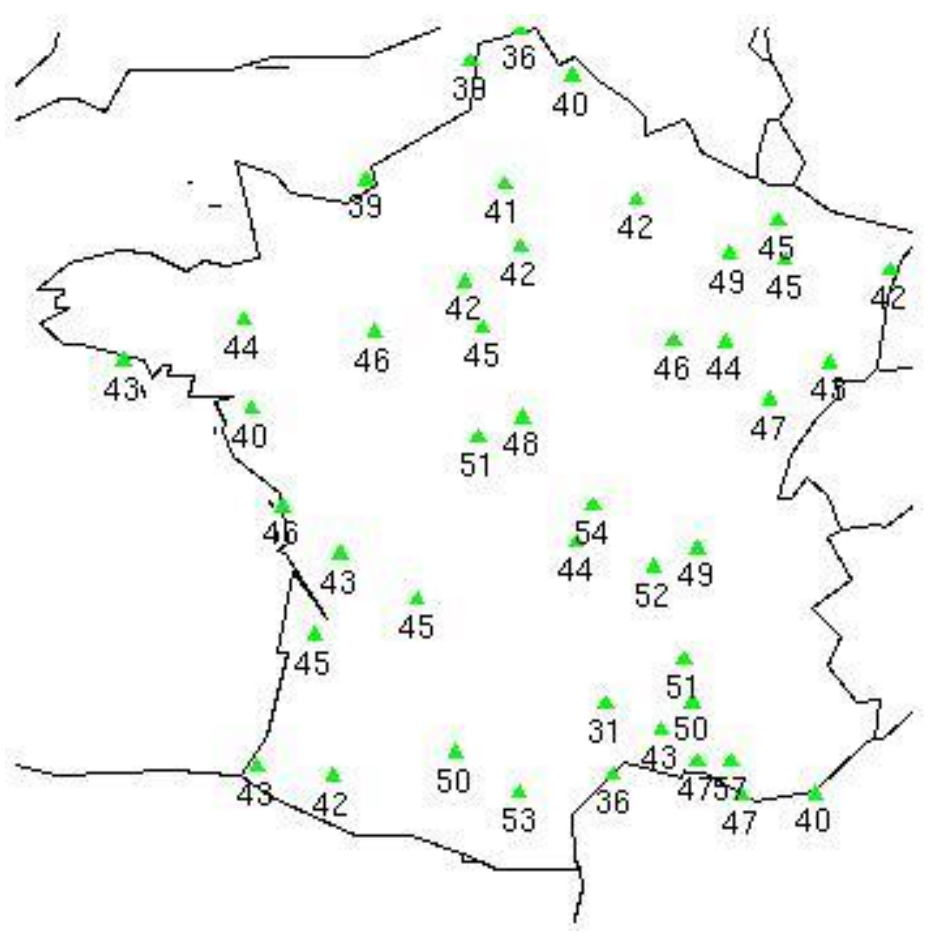

Figure 10 (Appendix 2)

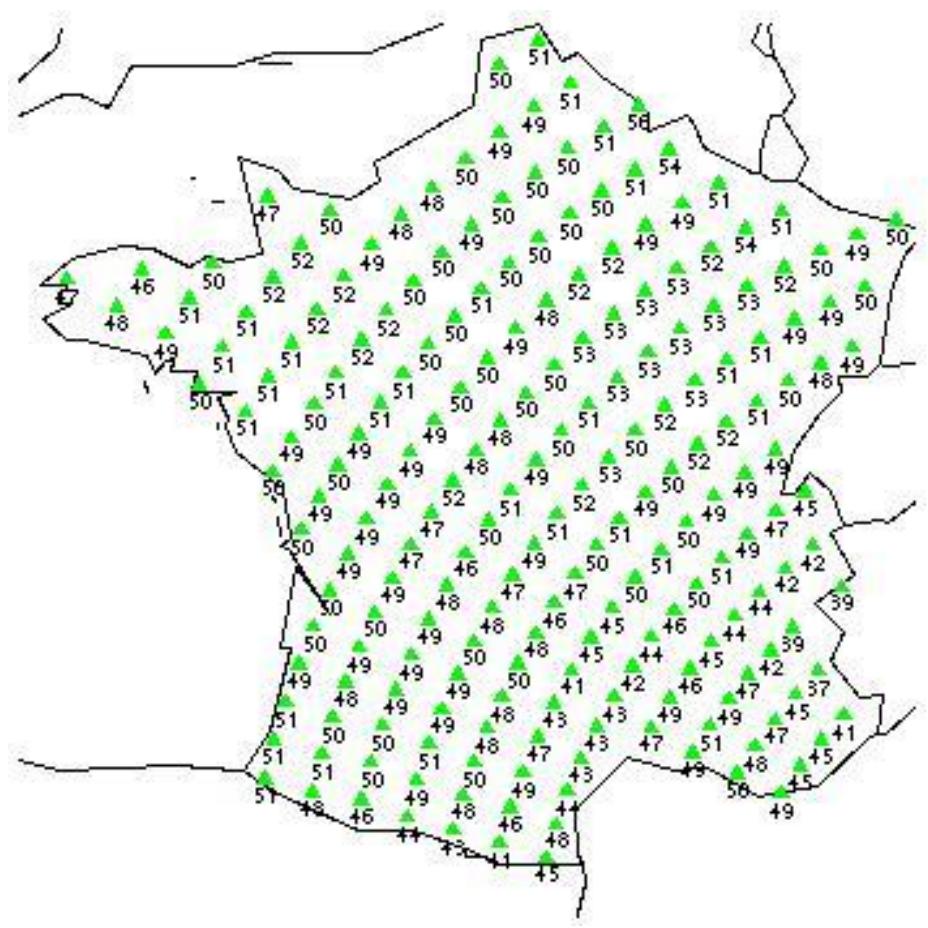

Figure 11 


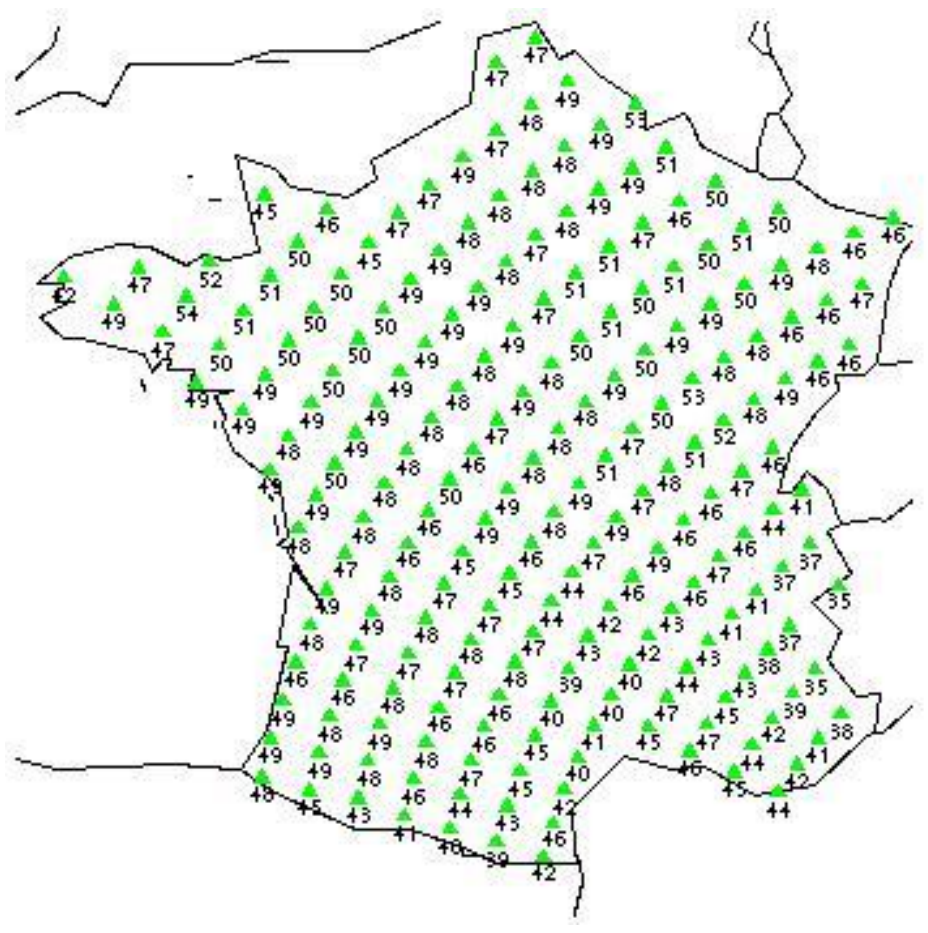

Figure 12

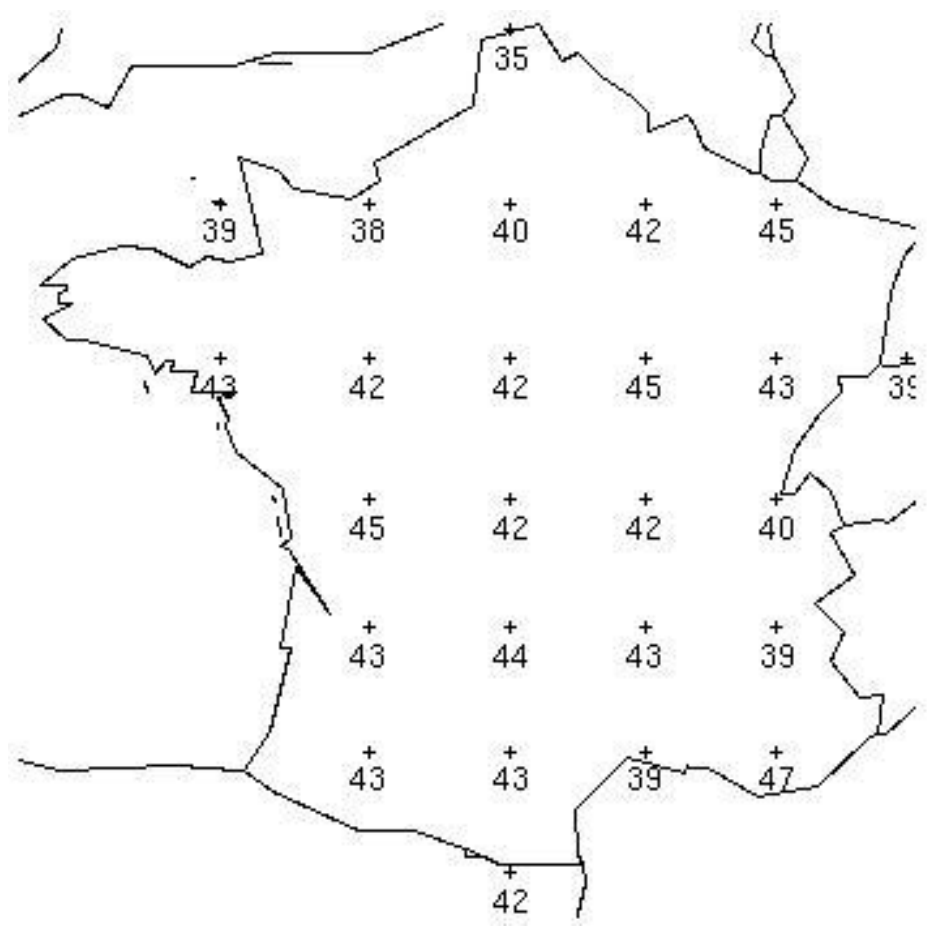

Figure 13 
Figure 1. Geographical position of the $55 \mathrm{SQR}$ stations of daily maximum temperature used in the present study.

Figure 2 Series repartition according to their beginning years (dashed bars) and to their ending years (full bars)

Figure 3. Grid points (crosses) labelled with their numbers from ARPEGE-Climat model (Météo-France) and SQR positions (triangles).

Figure 4. Grid points (crosses) labelled with their numbers from LMDZ model (CNRS/IPSL) and SQR positions (triangles).

Figure 5. Orange station. Maximum temperature (in ${ }^{\circ} \mathrm{C}$ ) per block of 25 days (over the period from 1960 to 2002 during the hot season) in function of the number of blocks (172 blocks in total here). The linear evolution of $\mu(t)$ is represented as a straight line.

Figure 6. Orange station. Temperatures (in ${ }^{\circ} \mathrm{C}$ ) above the threshold of $33,7^{\circ} \mathrm{C}($ over the period from 1960 to 2002 during the hot season) in function of the dates of these exceedances (in concatenated time).

Figure 7. 100-year-return-period temperatures (in ${ }^{\circ} \mathrm{C}$ ) estimated from a non-stationary extrapolation of SQR (from 1960 to 1999) with a quadratic model for I(t) and a stationary model for $\sigma(t)$ (noted OBS02 in the text).

Figure 8. Same figure as figure 6 but with a quadratic model for $I(t)$ and a linear model for $\sigma(t)$ (noted OBS12 in the text).

Figure 9. Same figure as figure 6 but from 1960 to 2003 (instead of 1999).

Figure 10. Same figure as figure 7 but from 1960 to 2003 (instead of 1999).

Figure 11. 100-year-return-period temperatures (in ${ }^{\circ} \mathrm{C}$ ) estimated from a stationary extrapolation of ARPEGE-Climat temperatures from 2070 to 2100 (A2 scenario).

Figure 12. Same figure as figure 10 but for a $\mathbf{B} 2$ scenario.

Figure 13. 100-year-return-period temperatures (in ${ }^{\circ} \mathrm{C}$ ) estimated from a stationary extrapolation of LMDZ temperatures around 2085 (A2 scenario). 